\title{
REVIEW
}

\section{Prone position in ARDS patients: why, when, how and for whom}

\author{
Claude Guérin ${ }^{1,2,3} \mathbb{D}$, Richard K. Albert ${ }^{4}$, Jeremy Beitler ${ }^{5}$, Luciano Gattinoni ${ }^{6}$, Samir Jaber ${ }^{7}$, John J. Marini ${ }^{8}$, \\ Laveena Munshi $^{9}$, Laurent Papazian ${ }^{10,11}$, Antonio Pesenti ${ }^{12}$, Antoine Vieillard-Baron ${ }^{13}$ and Jordi Mancebo ${ }^{14^{*}}$ (B)
}

(C) 2020 Springer-Verlag GmbH Germany, part of Springer Nature

\begin{abstract}
In ARDS patients, the change from supine to prone position generates a more even distribution of the gas-tissue ratios along the dependent-nondependent axis and a more homogeneous distribution of lung stress and strain. The change to prone position is generally accompanied by a marked improvement in arterial blood gases, which is mainly due to a better overall ventilation/perfusion matching. Improvement in oxygenation and reduction in mortality are the main reasons to implement prone position in patients with ARDS. The main reason explaining a decreased mortality is less overdistension in non-dependent lung regions and less cyclical opening and closing in dependent lung regions. The only absolute contraindication for implementing prone position is an unstable spinal fracture. The maneuver to change from supine to prone and vice versa requires a skilled team of 4-5 caregivers. The most frequent adverse events are pressure sores and facial edema. Recently, the use of prone position has been extended to non-intubated spontaneously breathing patients affected with COVID-19 ARDS. The effects of this intervention on outcomes are still uncertain.
\end{abstract}

Keywords: Acute respiratory distress syndrome, Prone position, Lung protective ventilation, Ventilation/perfusion, Gravity

\section{Introduction}

Prone position has been used for many years and is now recommended for patients with severe or moderateto-severe acute respiratory distress syndrome (ARDS) receiving invasive mechanical ventilation with sedation and paralysis. In the still ongoing coronavirus disease 2019 (COVID-19) pandemic prone position has largely been adopted by clinicians and is even used before intubation in patients breathing spontaneously. This article summarizes the physiologic effects of prone position, how to set the ventilator, the evidence of its effects on patients' outcome and future directions.

\footnotetext{
*Correspondence: jmancebo@santpau.cat

${ }^{14}$ Servei Medicina Intensiva, Hospital Universitari Sant Pau, Barcelona, Spain

Full author information is available at the end of the article
}

\section{Effects of prone position on lung/chest wall mechanics, ventilation, perfusion and gas exchange}

The lungs and chest wall, whose structures expand together and share identical volumes, have elastance properties that add in series: $\left(E_{\mathrm{rs}}=E_{1}+E_{\mathrm{w}}\right)$. Simultaneously, their compliance properties add in parallel: $C_{\mathrm{rs}}=\left[\left(C_{1} C_{\mathrm{w}}\right) /\left(C_{1}+C_{\mathrm{w}}\right)\right]$. Regional compliance of the lung and chest wall varies in response to differences in the anatomic shape of these structures, the local effects of gravity and the heterogeneous mechanical properties of the diseased lung. Therefore, in transitioning to the prone position, the compliance of the integrated respiratory system may stay unmodified, deteriorate or improve. These possible changes and their causes may best be understood by considering chest wall and lung separately.

\section{勿 Springer}




\section{Chest wall compliance}

Total chest wall compliance is influenced by the stiffness or flexibility of its three anatomic boundaries: anterior, posterior and abdominal. In the supine position, variations of compliance are most strongly influenced by the abdominal and the anterior chest wall, while in prone position, the posterior chest and abdomen are the key determinants. For anatomical reasons, the posterior chest wall (including spine and the scapulae) isless compliant than the anterior component (sternum and ribs). Conversely, in the prone position, the bed surface impedes expansion of the anterior structures while abdominal compliance remains relatively unmodified. Consequently, the natural response to prone position is a decrease in overall chest wall compliance [1].

\section{Lung compliance}

In ARDS patients, lung compliance is primarily determined by the lung open to ventilation (i.e., by the number of open pulmonary units). Of note, the specific lung compliance is similar in ARDS patients and in normal individuals, suggesting that surfactant alterations or early fibrosis do not predominate in altering the intrinsic mechanical characteristics of the lung [2]. It follows that any change in lung compliance is primarily due to the opening of new pulmonary units and/or to improved mechanical characteristics of already opened units that reach a more favorable position on the volume-pressure curve [3]. In the prone position such a favorable shift may result from promoting the homogeneous distribution of total stress and strain [4].

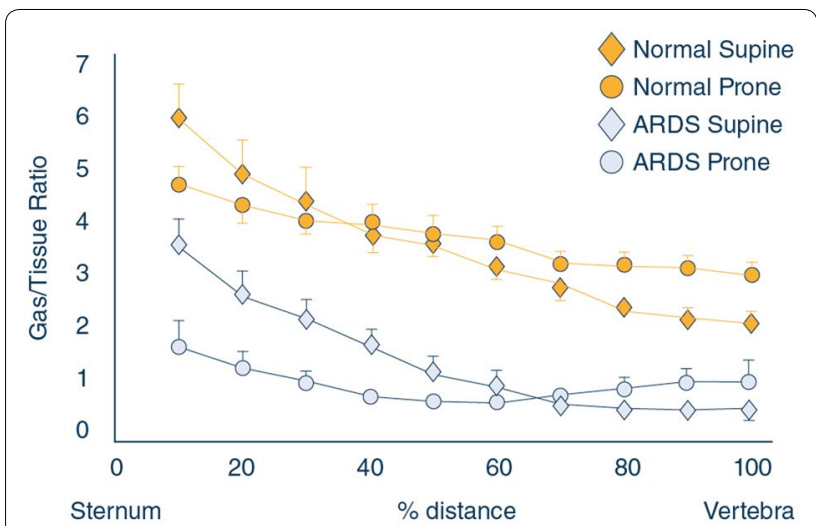

Fig. 1 The gas/tissue ratio (it may be thought as a volume of the pulmonary unit) as a function of the distance between the sternum and the vertebrae. As shown, in supine position, the gas/tissue ratio sharply decreases from the sternum to the vertebrae suggesting that both in normal and in ARDS patients the distending forces is about three times higher closer to the sternum than to the vertebrae. In prone position, the gas/tissue ratio is far more homogeneous, indicating a more even distribution of forces throughout the lung parenchyma

\section{Take-home message}

Prone positioning has now assumed its rightful place in the armentarium of ARDS management. In the still ongoing COVID-19 pandemic prone positioning has largely been adopted by clinicians and is even used before intubation in spontaneously breathing patients. This article summarizes the physiologic effects of prone positioning, how to set the ventilator, its beneficial effects on patients' outcome and future directions.

With these considerations in mind, the expected response to prone position and decreased overall compliance would be an increase in plateau pressure (in volume control ventilation) or a reduction of tidal volume (in pressure control ventilation). If these expected changes are not observed, it suggests improved lung compliance offsets the positional decrease in chest wall flexibility. Therefore, the simple observation of plateau pressure (or tidal volume) after a change from supine to prone may give an indication of the extent of lung recruitability.

\section{Ventilation and perfusion}

We believe it is extremely important to differentiate the concepts of inflation (a morphologic concept) and ventilation (a physiologic concept, consequence of inflating the lungs). The CT scan allows a precise quantification of the extent of the inflation as a ratio between gas and tissue. In Fig. 1, we represent the gas tissue ratio in prone and in supine position, both in normal and ARDS patients [5]. As shown, the inflation of the pulmonary units is far more homogeneous in prone compared to supine, meaning that the forces applied to distend the lungs (the trans-pulmonary pressure, i.e., the lung stress) are more homogeneously distributed [6]. The primary reason is improved shape matching between the chest wall and the lung [4]. The gravitational gradient of pleural pressure, regional end-expiratory and end-inspiratory lung volumes, regional ventilation and ventilation-perfusion ratios are all more uniform in the prone compared with the supine position [7-11].

Somewhat unexpectedly, perfusion distribution is similar in prone and supine positions [10, 12]. Importantly, counter to the zonal explanation for regional perfusion heterogeneity, the gravitational distribution of pulmonary blood flow is only minimally altered by turning prone resulting in the bulk of perfusion continuing to go to dorsal regions when these are turned to the nondependent position [13, 14]. It follows that the observed changes in gas exchange (a direct function of the ventilation/perfusion ratio) are primary due to changes in regional ventilation. 


\section{Recruitability}

The most striking change observed on CT scan when shifting from supine to prone position is the density redistribution from dorsal to ventral [15]. To interpret this finding, subsequent CT scan analyses culminated in the sponge model due to superimposed pressure [16]. Accordingly, in the wet lung, the progressive increase in pressure along the vertical axis from the lung weight squeezes gas from the most dependent lung units. Indeed, the most dorsal pulmonary units tend to be gasless in supine position [17]. This process is reversed (although not in a 1:1 ratio) by prone position. While prone, the dorsal, now nondependent pulmonary units, tend to open, while the ventral units, previously open, tend to collapse. It is worth noting that, usually, at the same airway pressure, the average density of the lung remains the same, as the tissue mass and the gas volume are not changed [15]. What may change, however, is gas distribution. Although it is often stated in the literature that prone position leads to recruitment [7], it is usually forgotten that repositioning is associated with collapse of the anterior lung regions although not in a 1:1 ratio. Therefore, the net effect of prone position on recruitability depends on the lung shape (i.e., the relative mass of dependent compared to non-dependent sectors), and the effect of the curvature of the diaphragm on transmission of the abdominal pressure. In a hypothetical, perfectly round lung and homogeneous diaphragm dome, the recruitability would be zero as the dorsal opening would equal ventral collapse. In reality, the mass of the dorsal lung is greater than the ventral, explaining a final net recruitment (see Fig. 2).

\section{Oxygenation}

We have now all the elements needed to discuss gas exchange in relationship to the prone position. Indeed, three elements, likely to different extents, may contribute to the improvement of oxygenation.

1. The first element is the quantity of tissue open to ventilation and perfusion during the respiratory cycle. If the recruitment of the dorsal lung exceeds the derecruitment of the ventral sectors, and because the distribution of perfusion is essentially unchanged, oxygenation should improve. Indeed, the perfusion remains the same, but the pulmonary units open to ventilation are more numerous when prone.

2. The second element is the degree of homogeneity of inflation. Inhomogeneity is associated with ventilation maldistribution. Given that perfusion remains nearly constant, more homogeneous ventilation results in more homogeneous distribution of ventila-

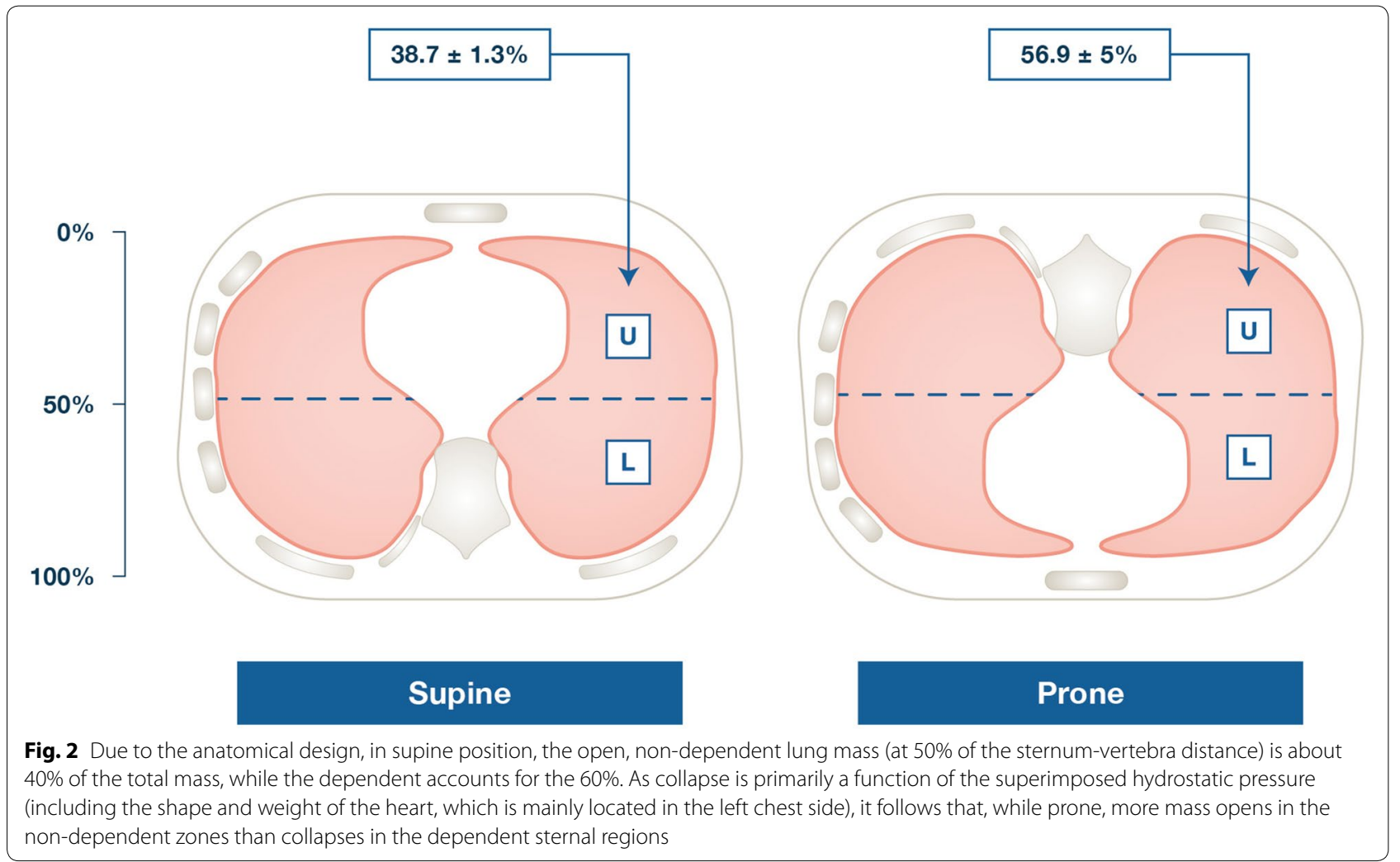


tion/perfusion ratios, which is reflected in decreased venous admixture and reduced dead space.

3. Regional changes in chest wall compliance may also contribute to improved oxygenation. Indeed, due to the lower compliance of the anterior chest wall and the curvature of the diaphragm, the distribution of tidal volume moves towards the posterior, paraabdominal regions of the lung, where supine ventilation is usually absent.

The improvement results from a reduction in shunt and ventilation-perfusion heterogeneity that occurs because the lungs, which anatomically resemble a cone, fit into their cylinder-like thorax enclosure with less distortion when patients are prone versus supine $[12,18-20]$. This, in turn, decreases atelectasis in dorsal lung regions where shunt is preferentially distributed in ARDS [7, 12].

\section{Carbon dioxide elimination}

A variable that is usually ignored is the $\mathrm{PaCO}_{2}$ response to prone position. When prone position is associated with decreased $\mathrm{PaCO}_{2}$ for the same minute ventilation, clinical outcome appears more favorable [21]. Recruitment of perfused and previously collapsed units results in reduced shunt and thus favors a reduction in $\mathrm{PaCO}_{2}$ [22]. Furthermore, more homogeneous inflation should be associated with a decreased dead space originating from pulmonary units that were relatively overinflated while supine. We may then wonder about the possible mechanisms that would increase $\mathrm{PaCO}_{2}$ after proning. In unadjusted pressure controlled ventilation, the reduction of chest wall compliance in the prone position would tend to reduce tidal volume and consequently reduce alveolar ventilation. If in volume controlled ventilation the increase in pleural pressure due to the decreased chest wall compliance may reduce venous return, and if accompanied by a reduction of regional perfusion, will increase dead space.

\section{Prone position and hemodynamics}

In the APRONET study, one of the most frequently reported reasons for not doing prone position was a mean arterial pressure below $65 \mathrm{mmHg}$ [23]. However, hemodynamic impairment, a frequent condition in ARDS, is not by itself a contraindication to prone position. In the PROSEVA trial, which demonstrated a beneficial effect of prone position on survival, $72 \%$ of patients in the prone position group received vasopressors, a rate not different from the control group. However, all patients were hemodynamically stable at the time of inclusion as a mean arterial pressure not maintained $\geq 65 \mathrm{mmHg}$ was an exclusion criterion [24]. It is crucial to emphasize that prone position, when adequately performed, does not induce hemodynamic side effects and that it may even improve hemodynamics [25].

In a systematic review and meta-analysis, hemodynamic impairment was not described among the few side effects of prone position and, patients in prone position had lower incidence of arrhythmias [26]. It is likely that the way physicians perform prone position may modify its impact on hemodynamics. Chiumello et al. have reported that prone position when done with thoracopelvic supports significantly decreased stroke volume and increased heart rate, while no effect was observed when prone position was done without any support, possibly because pelvic support could have decreased venous return [27]. Some configurations of thoracic support have the potential to increase intrathoracic pressure, which may potentially decrease systemic venous return.

One of the most interesting physiological effects of prone position is that it may also improve hemodynamics. In the PROSEVA study, Guerin et al. observed less cardiac arrests in the prone position group $(6.8 \%$ versus $13.5 \%)$ and the number of extra-pulmonary dysfunction-free days up to 28 days after randomization was also higher [24]. In 18 ARDS patients, all with a dilated right ventricle before proning, Jozwiak et al. reported that cardiac index did not change in around half of the patients and increased in the other half, which was associated with right ventricle unloading [28]. The patients in whom cardiac index increased, had a preload-dependent cardiac index when supine [28]. In a series of 42 severe ARDS patients, prolonged proning $(18 \mathrm{~h})$ led to the normalization of right ventricle function in the 21 patients who initially had right ventricle systolic overload, named acute cor pulmonale. This right ventricle unloading was associated with a significant increase in cardiac index and a decrease in heart rate [29]. These effects may be explained by the impact of prone position on respiratory mechanics and blood gas exchange (Fig. 3). As a matter of fact, hypoxemia, hypercapnia, high driving pressure and plateau pressure $\geq 27 \mathrm{cmH}_{2} \mathrm{O}$ are risk factors for developing acute cor pulmonale [30, 31]. By recruiting the lungs, prone position has the potential to decrease hypoxemia, hypercapnia, driving pressure and plateau pressure and thereby improve right ventricular function and hemodynamics. When clinically indicated in ARDS patients, inhaled nitric oxide should be better used in prone position because its additive effects on oxygenation and pulmonary circulation [32]. Another potential mechanism is its ability to avoid applying too high PEEP, which has been reported to decrease survival and induce deleterious effects on hemodynamics when applied after aggressive staircase recruitment maneuvers [33]. How the effect of prone position on hemodynamics in general and on right ventricle function in particular may 
Supine Position before proning

\begin{tabular}{|c|c|c|c|}
\hline $\begin{array}{c}\mathrm{PaO}_{2} / \mathrm{FiO}_{2} \\
(\mathrm{mmHg})\end{array}$ & $\begin{array}{c}\mathrm{PaCO}_{2} \\
(\mathrm{mmHg})\end{array}$ & $\begin{array}{c}\mathrm{P}_{\text {plat }} \\
\left(\mathrm{cmH}_{2} \mathrm{O}\right)\end{array}$ & $\begin{array}{c}\text { DrivingP } \\
\left(\mathrm{cmH}_{2} \mathrm{O}\right)\end{array}$ \\
\hline \hline 74 & 54 & 27 & 21 \\
\hline
\end{tabular}

Supine position after 18 hours of proninig

\begin{tabular}{|c|c|c|c|}
\hline $\begin{array}{c}\mathrm{PaO}_{2} / \mathrm{FiO}_{2} \\
(\mathrm{mmHg})\end{array}$ & $\begin{array}{c}\mathrm{PaCO}_{2} \\
(\mathrm{mmHg})\end{array}$ & $\begin{array}{c}\mathrm{P}_{\text {plat }} \\
\left(\mathrm{cmH}_{2} \mathrm{O}\right)\end{array}$ & $\begin{array}{c}\text { DrivingP } \\
\left(\mathrm{cmH}_{2} \mathrm{O}\right)\end{array}$ \\
\hline 115 & 50 & 25 & 19 \\
\hline
\end{tabular}

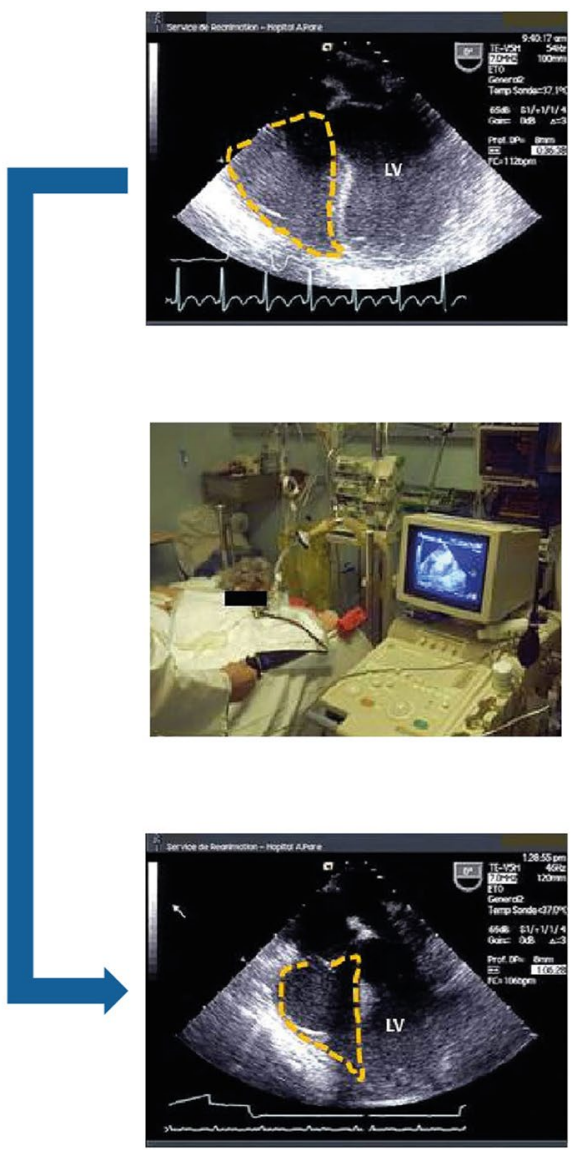

Fig. 3 Improvement in right ventricular (RV) function after a proning session of $18 \mathrm{~h}$ in a patient ventilated for a severe ARDS. Long-axis midesophageal view by transesophageal echocardiography shows major RV dilatation (dotted yellow line) before prone positioning (upper image) and normalization when supine positioning was performed after several hours of proning (lower image). Main risk factors for RV overload are reported before and after in the tables. Pplat plateau pressure, DrivingP driving pressure, $L V$ left ventricle

participate to its beneficial effect on outcome remains to be determined. We already know that improvement in blood gases does not explain the increase in survival observed in the PROSEVA study [34]. In other words, prone position could be beneficial in responders as well as non-responders when they are conventionally defined by changes in gas exchange parameters.

\section{Clinical indications - for whom and when-and contraindications}

There are two primary indications for implementing prone ventilation in patients with ARDS: the need to improve oxygenation, as previously discussed, and the potential for prone position to reduce mortality.

Although large animal studies demonstrated clear lung protective effects of prone positioning $[35,36]$, early randomized trials conducted in unselected patients with oxygenation failure found that prone ventilation had no effect on mortality. Accordingly, for many years proning was only utilized as rescue therapy for severe hypoxemia. In retrospect, however, all of these early studies had methodological concerns that could have resulted in false negative conclusions (e.g., being under-powered to detect differences in mortality, only exposing patients to short durations of proning each day, using excessive sedation) [37].

In 2013, Guerin and colleagues found that prone ventilation employed at least $16 \mathrm{~h}$ /day reduced 90-day mortality from 41 to $23.6 \%$ with no substantive adverse effects in patients with $\mathrm{PaO}_{2} / \mathrm{F}_{\mathrm{I}} \mathrm{O}_{2}$ ratio $<150 \mathrm{mmHg}$ [24]. Despite this striking result, 5 years later prone ventilation was only being used in 33\% of patients with severe ARDS. The most common explanation for why it was not being used was that oxygenation was not sufficiently impaired [23], perhaps in large part a carry-over from the idea that proning should only be used as rescue therapy for severe 
hypoxemia. Perceived increase in workload and inadequate availability of trained staff likely contributed, as well.

In prone position, there is less over-distension in nondependent lung regions and less cyclical airspace opening and closing in dependent regions, the putative causes of ventilator-induced lung injury $[7,38]$. To the extent that ventilator-induced lung injury complicates ARDS these beneficial effects suggest that prone ventilation should be implemented early rather than late in the course of the syndrome. Importantly, these effects occur in all lungs, even those that are completely normal and will therefore also occur in patients with mild or moderate ARDS. Several studies, however, report that prone ventilation does not reduce mortality for patients with $\mathrm{PaO}_{2} / \mathrm{F}_{\mathrm{I}} \mathrm{O}_{2}$ ratio $>150 \mathrm{mmHg}$, but these are again under-powered for a mortality endpoint and/or were confounded by use of substantially greater levels of sedation. Interestingly, the confidence intervals in two meta-analyses of these studies indicate that additional trials might reduce mortality to a clinical meaningful extent in patients with mild or moderate ARDS [37]. In addition, it can be argued that the use of deep sedation and muscle paralysis is not mandatory for all patients. Instead, individual titration of these drugs is advised for routine clinical practice.

\section{Contraindications}

The only absolute contraindication of prone positioning is an unstable spinal fracture. Relative contraindications include hemodynamic instability, unstable pelvic or long bone fractures, open abdominal wounds and increased intracranial pressure that occurs if positioning of the head and neck partially obstructs cerebral venous drainage. In the latter instance, however, intracranial pressure can be measured and used as guidance to facilitate positioning to avoid this adverse effect. Patients with rheumatoid arthritis affecting the atlanto-occipital joint should not be proned until a neck collar has been placed. Massive obesity, an increasing ICU population worldwide, should not be considered a contraindication, as these patients often benefit. Late-term pregnancy has been suggested as a contraindication, but proper positioning to limit abdominal and pelvic compression and utilizing continuous monitoring of fetal heart tones allows proning of these patients as well. Some of these relative contraindications can be discussed on a case-by-case basis with the clinical team involved in the patient care.

\section{Choice of ventilator settings}

In ARDS, prone position may have synergistic lungprotective effects with low tidal volume ventilation. The survival benefit of prone position appears dependent on concomitant use of low tidal volumes [39]. The mechanisms explaining the survival benefit of prone position in ARDS have been already discussed.

Proning also may have synergistic effects with PEEP $[40,41]$. Increasing PEEP in the heterogeneously aerated supine ARDS lung can induce lung recruitment and decrease atelectrauma at the expense of exacerbating end-tidal regional hyperinflation. Because prone positioning lessens heterogeneity of regional lung strain and decreases chest wall compliance [42], higher PEEP may be less likely to contribute to regional hyperinflation with proning [40].

When considering ventilator settings for the prone ARDS patient, at a minimum patients should receive support consistent with the PROSEVA trial [24]. Such settings would include low tidal volumes targeting around $6 \mathrm{~mL} / \mathrm{kg}$ predicted body weight, plateau airway pressure less than $30 \mathrm{cmH}_{2} \mathrm{O}$, with reduction in tidal volume as needed to achieve this goal, and at least moderate PEEP levels.

However, a few considerations suggest potentially more protective settings may be feasible with prone positioning. First, proning is often accompanied by continuous neuromuscular blockade [24]. Thus, potential trade-offs of deeper sedation and paralytics sometimes required for patient tolerance of ventilator settings are a non-factor when the decision to prone has been made. Second, proning often improves oxygenation and reduces deadspace ventilation [43]. Improvements in gas exchange do not appear to predict survival benefit [34, 44], but they do create an opportunity to modify ventilator settings further before confronting limits of severe hypercapnia or hypoxemia. Thus, it may be beneficial to exploit proning-associated improvement in gas exchange and concomitant neuromuscular blockade to lower tidal volumes below $6 \mathrm{~mL} / \mathrm{kg}$ predicted body weight to the lowest values tolerated, or considering permissive hypercapnia as appropriate. PEEP titration is not likely to exhibit a unidirectional or linear relationship with lung protection even in context of neuromuscular blockade and proning [41]. If set too low, end-tidal collapse of small airways might occur, predisposing to atelectrauma, and lung may derecruit gradually over time, decreasing the aerated baby lung volume available for tidal ventilation [45]. If set too high, PEEP unequivocally can exacerbate end-tidal hyperinflation and hemodynamic instability [45]. The ideal PEEP titration strategy, irrespective of patient positioning, remains undefined, in part because how to address this competing tension between preventing atelectrauma and hyperinflation is unclear. It is worth emphasizing, however, that the effects on overdistension and atelectrauma will be less with prone position as compared to supine. 
Lowering tidal volume to the lowest tolerated value helps mitigate this tension of PEEP titration by decreasing risk of both atelectrauma and hyperinflation [45]. Clinical trials of prone positioning with patient-centered endpoints have consistently used relatively low PEEP strategies $[5,41]$ but have not attempted to lower tidal volume lower than $6 \mathrm{~mL} / \mathrm{kg}$ predicted body weight so long as plateau pressure did not exceed $30 \mathrm{cmH}_{2} \mathrm{O}$. If even lower tidal volumes were targeted, higher PEEP could be instituted to homogenize lung aeration and regional mechanics with less risk of end-tidal tidal hyperinflation. While synergistic effects have been suggested $[40,41]$, the potential for clinical benefit is untested.

Regardless, whenever ventilator adjustments are made during prone position, reevaluation is warranted each time the patient is returned to supine position to ensure ventilator settings remain safe and well tolerated. Changes in gas exchange and mechanics with re-supination may necessitate ventilator adjustments with each turn.

\section{How to implement prone position at the bedside}

Absolute or relative contraindications to prone position have been previously mentioned. In contrast, prone position can be performed in ECMO and ECCO2-r patients. In a recent international survey involving 23 ECMO centers, prone position was used in $6 \%$ of the patients at ECMO day 1 and in $15 \%$ of the patients throughout their ECMO course [46]. Unfortunately, prone position was used in only $26 \%$ of the cases before ECMO initiation [46].

\section{Beds}

Various types of bed are used. Many times, standard intensive care unit beds are used as in the PROSEVA study [24]. Low-air loss bed system is also employed in some ICUs [47]. In contrast, automated pronating beds are not used in many instances to prone the patients [48].

\section{Prone position maneuver}

There are many different ways to place a patient in the prone position. Local protocols should be followed when undertaking the maneuver to reduce the risk of injury to staff (back injuries) and patients. Usually, patients are placed with the arms parallel to the trunk or in swimming "crawl" position, the abdomen unsupported, and with the face turned to the right or the left side. Such positions are changed every $2-4 \mathrm{~h}$. Although eyes occlusion is recommended to prevent conjunctivitis and corneal ulcerations, application of thin hydrocolloid dressing for pressure ulcer prevention is controversial. Meticulous securing of endotracheal tube and intravascular catheters is mandatory. Positioning of transverse rolls placed under the pelvis and the chest has not been proved to improve oxygenation, and often results in a decrease in chest wall compliance and an increased pleural pressure $[27,49]$. For patients with tracheostomy, specially designed disposable prone position head cushion with mirror improves the access to the endotracheal tube and facilitates endotracheal suctioning using a closed-system. The standard monitoring during the entire procedure should include pulse oximetry and invasive arterial blood pressure. In order to avoid complications, the proning maneuver requires practical skills and a complex and coordinated effort, involving physicians and nurses. When prone position is performed in ECMO patients $[50,51]$, at least six staff are involved, four performing the turning of the patient, one looking after the ECMO circuit and one (usually a physician) for the management and protection of the endotracheal tube (See video). It should be noted that without the particular pillow shown in the video, in particular when there is no cervical problem, prone position could also be implemented.

\section{Duration of prone position}

Research suggests that the longer a patient is given prone therapy, the greater the benefits [52, 53]. It is essential to underline that in the PROSEVA study [24], the prone position was done every day even if there was no improvement in oxygenation during the previous session. Indeed, the mechanisms explaining the outcome improvement are complex and not likely to be limited to the improvement in gas exchange. The localization of lung infiltrates (chest X-ray, lung ultrasound, CT-scan) does not predict the improvement in oxygenation $[54,55]$ even in ECMO patients [51]. When prone position was indicated by the lung morphology a trial found no benefit to patient outcome [56]. The usual criteria for stopping prone treatment are oxygenation improvement with the possibility of using a ventilatory mode allowing spontaneous or assisted ventilation, $\mathrm{PaO}_{2} / \mathrm{F}_{\mathrm{I}} \mathrm{O}_{2}$ ratio deterioration by more than $20 \%$ relative to supine or the occurrence of a life-threatening complication during prone position [24].

\section{Adverse events}

Various complications can occur during transitions to and from prone position, such as device displacement, vomiting, loss of venous access, accidental extubation, endotracheal tube displacement and obstruction, hemodynamic instability, brachial plexus injury and pressure ulcers [48]. Ocular complications, like increased intra-ocular pressure, have been described during prolonged prone position in normal volunteers [57]. Data in ARDS patients are scanty. A trial is ongoing testing strategies to prevent complications in prolonged prone 


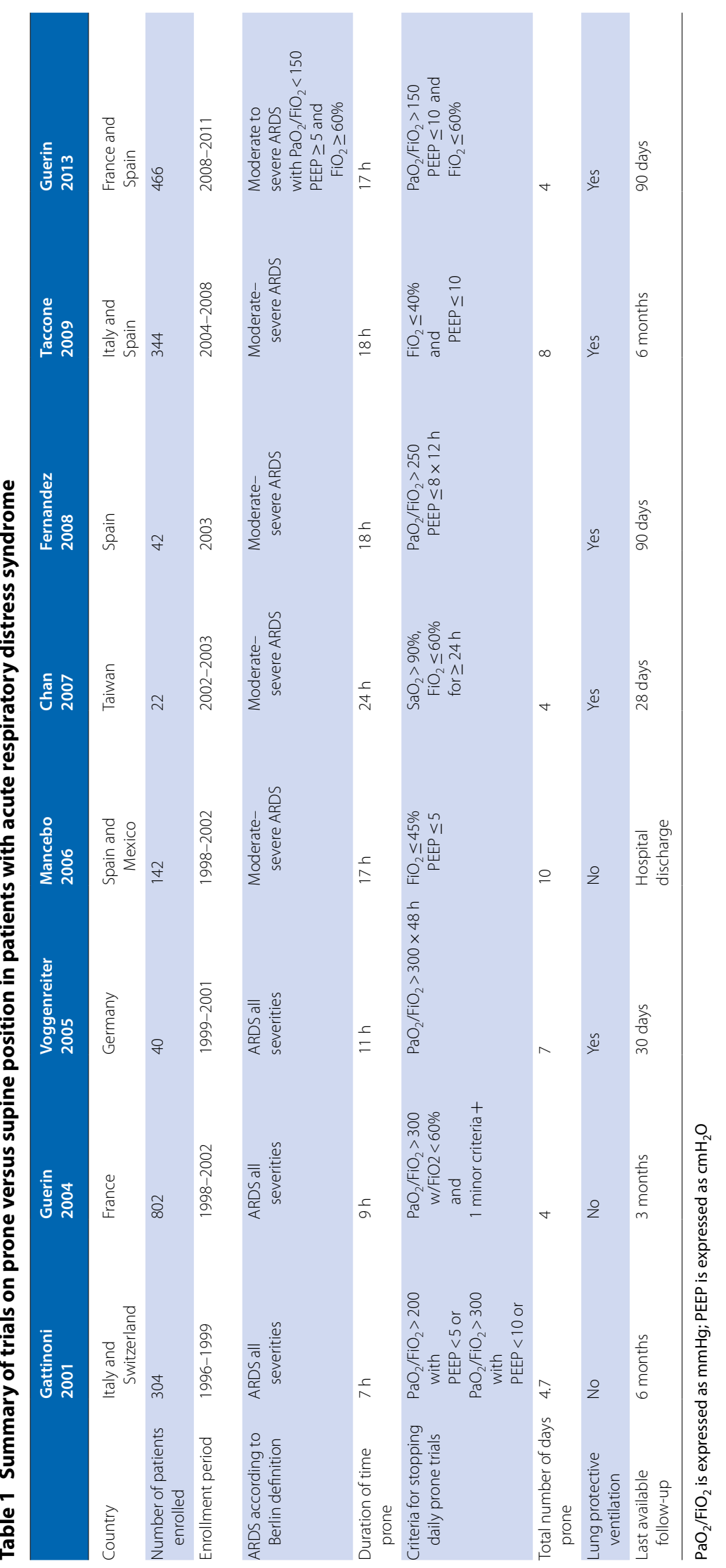


position sessions, including the ocular, in ARDS patients (NCT03125421). It has been suggested, however, that the incidence of barotrauma, ventilator-associated pneumonia, accidental catheter removal and unplanned extubation is not different between prone position and supine position while endotracheal tube obstruction and pressure sores increased with prone position [58]. In the PROSEVA trial [24], for example, there was no difference between the prone position group and the supine group regarding the incidence of accidental extubation, selective bronchial intubation or endotracheal tube obstruction. Likely, such complications can be avoided with staff training and collaboration. Once settled into the prone position, consequences and nursing workload related to maintaining the prone position are not increased. Reversible facial edema, however, is predictable when prone position is sustained. Only minor complications have been reported in ECMO patients [50,51], but again, these procedures must be performed by very experienced and trained teams. Priority must be given to the safety in order to maximize benefits and minimize harm. Continuous education and training should be provided to the caregivers [59].

Other risk factors for pressure ulcers than prone position duration are observed in ARDS patients such as age, hemodynamic instability, other organ dysfunctions, length of stay in the ICU, immobilization and nutritional status. It has been reported that at day 7 , the rate of patients with pressure ulcers was higher in the prone position group than in the supine group (face and anterior part of the thorax) [60]. However, at the time of ICU discharge, the rate of patients with pressure ulcers was no longer different between groups [48].

\section{Clinical impact on outcomes and summary of trials}

The role of mechanical ventilation in the prone position has undergone rigorous evaluation over the past 3 decades [58]. The evolution of the study designs demonstrates how-with time and synthesis of prior studies-the optimal manner of delivery and right population may come to fruition over time.

Preliminary studies of prone position have consistently demonstrated an improvement in oxygenation across all severities of acute respiratory failure [61-64]. Furthermore, the impact on oxygenation has been found to be sustained when returned to ventilation in supine position. But as previous studies across the ARDS literature have demonstrated, improving oxygenation does not always translate to important patient-centered clinical outcomes such as mortality [65].

Interestingly, mortality was not impacted by prone position until more recent studies. Early studies were characterized by including all severities of ARDS, shorter durations of prone position and lower thresholds to terminate daily prone position sessions (Table 1) [62, 63]. However, a meta-analysis pooling data from the 4 largest studies in 2010 demonstrated a mortality benefit across the subgroup of severely hypoxemic patients [48, 62-64, 66]. It was theorized that this cohort likely derives the greatest benefit from the physiologic impact of prone position given the greater amount of edema and alveolar collapse.

The totality of the literature prior to 2013 established the groundwork for the most recent trial of prone position in moderate-severe ARDS by Guerin and colleagues [24]. Across the 466 patients enrolled in the PROSEVA trial, 28 -day mortality was $16 \%$ in the prone group and $33 \%$ in the supine group $(p<0.001$; hazard ratio for death with prone position was 0.39 ( $95 \%$ confidence interval (CI) $0.25-0.63$ ).

In a meta-analysis, eight randomized trials (2129 patients) over 12 years, the effect of prone position across all severities of ARDS was evaluated. Prone position conducted for greater than $12 \mathrm{~h}$ per day and studies restricted to moderate to severe ARDS were associated with a mortality benefit [RR 0.74 (95\% CI 0.56-0.99)] [58]. Prone position has consistently appeared to benefit the more hypoxemic subset of patients with ARDS; however, given the lack of granularity of the pooled data, an evaluation of the specific $\mathrm{PaO}_{2} / \mathrm{FiO}_{2}$ threshold of $150 \mathrm{mmHg}$ was not feasible. Up until this point, however, pooled data have demonstrated a consistent benefit across severe ARDS [7]. The 2017 American Thoracic Society/European Society of Intensive Care Medicine/Society of Critical Care Medicine clinical practice guideline of mechanical ventilation in adult patients with ARDS strongly recommended that patients with severe ARDS receive prone positioning for more than $12 \mathrm{~h}$ per day [67]. The 2019 guidelines of the French Society of Intensive Care Medicine (SRLF) for ARDS management strongly recommended the implementation of prone position in ARDS patients with a $\mathrm{PaO}_{2} / \mathrm{FiO}_{2}$ ratio below $150 \mathrm{mmHg}$ [68]. Because no trial has been specifically performed in mild to moderate ARDS patients [37], a French trial is in preparation to evaluate the specific $\mathrm{PaO}_{2} / \mathrm{FiO}_{2}$ threshold at which prone position is beneficial.

\section{Unanswered questions, new avenues of research and conclusion}

Prone position has been shown effective in patients with moderate to severe ARDS, who received invasive mechanical ventilation, a continuous infusion of neuromuscular blockade and low tidal volume [24]. Whereas prone position seemed underutilized, the COVID-19 pandemic showed that actually clinicians adopted this strategy widely. For instance, $76 \%$ of the 735 
COVID-19-related ARDS patients included in a multicenter cohort in Spain were proned, and prone was used in $63 \%$ of the mild ARDS patients [69]. Studies in progress indicate that the mechanisms of action in COVID19 pneumonia (for example redistribution of blood flow) may differ from those in other more familiar forms of ARDS [70], and authors have underlined that not all COVID-19 intubated mechanically ventilated patients can benefit of prone positioning [71].

Even though long prone position sessions are advocated, the optimal duration is not definitely determined. Multimodality monitoring including lung and chest wall mechanics [72], electrical impedance tomography [73] and biomarkers may help clinicians to better determine the time to move the patient back to supine and/or to resume the prone position.

How ventilator settings should be adjusted in prone position is an unanswered issue. Clinicians mostly reduce $\mathrm{FiO}_{2}$ as a result of the better oxygenation commonly observed with pronation. In trials, PEEP level in prone was found lower than expected [41], even though a low PEEP level may have contributed to the clinical benefit [24]. An attempt to use the esophageal pressure-guided strategy in prone failed, on average, to show physiological benefit as compared to a PEEP and $\mathrm{FiO}_{2}$ table in humans [74] in line with experimental data [75].

Even though already in the pipeline (NCT04142736), the use of prone in spontaneously breathing non-intubated patients has been boosted by the COVID-19 pandemic. To date results of observational studies reporting on the feasibility and efficacy on oxygenation of this strategy before intubation, in patients receiving high flow oxygen or non-invasive ventilation, are balanced [76, 77]. Trials are planned to verify if this strategy can reduce the rate of intubation and improve survival (NCT04391140).

In conclusion, prone position has now assumed its rightful place in the armamentarium of management of ARDS, and it would be important to know if prone position in non-intubated patients can also confirm its beneficial impact on clinical outcomes.

\section{Electronic supplementary material}

The online version of this article (https://doi.org/10.1007/s00134-020-06306 -w) contains supplementary material, which is available to authorized users.

\footnotetext{
Author details

${ }^{1}$ Médecine Intensive-Réanimation, Hôpital Edoudard Herriot, Lyon, France. ${ }^{2}$ University of Lyon, Lyon, France. ${ }^{3}$ Institut Mondor de Recherche Medicale INSERM 955, ERL CNRS 7000, Créteil, France. ${ }^{4}$ Department of Medicine, University of Colorado, Aurora, USA. ${ }^{5}$ Center for Acute Respiratory Failure and Division of Pulmonary, Allergy, and Critical Care Medicine, Columbia University College of Physicians and Surgeons, New York, NY, USA. ${ }^{6}$ Department of Anesthesiology, Emergency and Intensive Care Medicine, University of Göttingen, Göttingen, Germany. ${ }^{7}$ Critical Care and Anesthesia Department (DAR B), Hôpital Saint-Éloi, CHU de Montpellier, PhyMedExp, Université de Montpellier, Montpellier, France. ${ }^{8}$ Departments of Critical Care Medicine, Regions Hospital
}

and University of Minnesota, Minneapolis-St. Paul, USA. ${ }^{9}$ Interdepartmental Division of Critical Care Medicine, Mount Sinai Hospital, Sinai Health System, University of Toronto, Toronto, Canada. ${ }^{10}$ Médecine Intensive Réanimation, Assistance Publique, Hôpitaux de Marseille, Hôpital Nord, 13015 Marseille, France. ${ }^{11}$ Faculté de Médecine, Groupe de Recherche en Réanimation Et Anesthésie de Marseille Pluridisciplinaire (GRAM +), Aix-Marseille Université, Centre d'Etudes et de Recherches sur les Services de Santé et qualité de vie EA 3279, 13005 Marseille, France. ${ }^{12}$ Dipartimento Di Anestesia, Rianimazione ed Emergenza Urgenza, Fondazione IRCCS Cà Granda-Ospedale Maggiore Policlinico, Milan, Italy. ${ }^{13}$ University Hospital Ambroise Paré, APHP, BoulogneBillancourt, and Université de Versailles Saint Quentin en Yvelines UMR 1018, Boulogne-Billancourt, France. ${ }^{14}$ Servei Medicina Intensiva, Hospital Universitari Sant Pau, Barcelona, Spain.

\section{Funding}

None.

\section{Compliance with ethical standards}

\section{Conflicts of interest}

SJ reports receiving consulting fees from Drager, Medtronic, Baxter, Fresenius Medical and Fisher and Paykel. LP received consultancy fees from Air Liquide MS, Faron and MSD. JM reports personal fees from Faron, Medtronic, and Janssen, outside the submitted work (last 36 months).

\section{Publisher's Note}

Springer Nature remains neutral with regard to jurisdictional claims in published maps and institutional affiliations.

Received: 8 October 2020 Accepted: 19 October 2020

Published online: 10 November 2020

\section{References}

1. Pelosi P, Tubiolo D, Mascheroni D, Vicardi P, Crotti S, Valenza F, Gattinoni $L$ (1998) Effects of the prone position on respiratory mechanics and gas exchange during acute lung injury. Am J Respir Crit Care Med 157:387-393

2. Gattinoni L, Pesenti A (2005) The concept of "baby lung." Intensive Care Med 31:776-784

3. Chiumello D, Marino A, Brioni M, Cigada I, Menga F, Colombo A, Crimella F, Algieri I, Cressoni M, Carlesso E, Gattinoni L (2016) Lung recruitment assessed by respiratory mechanics and computed tomography in patients with acute respiratory distress syndrome. What is the relationship? Am J Respir Crit Care Med 193:1254-1263

4. Gattinoni L, Taccone P, Carlesso E, Marini JJ (2013) Prone position in acute respiratory distress syndrome. Rationale, indications, and limits. Am J Respir Crit Care Med 188:1286-1293

5. Tobin MJ (1994) Mechanical ventilation. N Engl J Med 330:1056-1061

6. Guerin C, Baboi L, Richard JC (2014) Mechanisms of the effects of prone positioning in acute respiratory distress syndrome. Intensive Care Med 40:1634-1642

7. Galiatsou E, Kostanti E, Svarna E, Kitsakos A, Koulouras V, Efremidis SC, Nakos G (2006) Prone position augments recruitment and prevents alveolar overinflation in acute lung injury. Am J Respir Crit Care Med 174:187-197

8. Mutoh T, Guest RJ, Lamm WJ, Albert RK (1992) Prone position alters the effect of volume overload on regional pleural pressures and improves hypoxemia in pigs in vivo. Am Rev Respir Dis 146:300-306

9. Mure M, Domino KB, Lindahl SG, Hlastala MP, Altemeier WA, Glenny RW (2000) (2000) Regional ventilation-perfusion distribution is more uniform in the prone position. J Appl Physiol (1985) 88:1076-1083

10. Musch G, Layfield JD, Harris RS, Melo MF, Winkler T, Callahan RJ, Fischman AJ, Venegas JG (2002) Topographical distribution of pulmonary perfusion and ventilation, assessed by PET in supine and prone humans. J Appl Physiol 93:1841-1851

11. Henderson AC, Sa RC, Theilmann RJ, Buxton RB, Prisk GK, Hopkins SR (2013) The gravitational distribution of ventilation-perfusion ratio is more 
uniform in prone than supine posture in the normal human lung. J Appl Physiol (1985) 115:313-324

12. Lamm WJ, Graham MM, Albert RK (1994) Mechanism by which the prone position improves oxygenation in acute lung injury. Am J Respir Crit Care Med 150:184-193

13. Wiener CM, KirkW, Albert RK (1990) Prone position reverses gravitational distribution of perfusion in dog lungs with oleic acid-induced injury. J Appl Physiol 68:1386-1392

14. Glenny RW, Lamm WJ, Albert RK, Robertson HT (1991) Gravity is a minor determinant of pulmonary blood flow distribution. J Appl Physiol (1985) 71:620-629

15. Gattinoni L, Pelosi P, Vitale G, Pesenti A, D'Andrea L, Mascheroni D (1991) Body position changes redistribute lung computed-tomographic density in patients with acute respiratory failure. Anesthesiology 74:15-23

16. Bone RC (1993) The ARDS lung. New insights from computed tomography. JAMA 269:2134-2135

17. Pelosi P, D'Andrea L, Vitale G, Pesenti A, Gattinoni L (1994) Vertical gradient of regional lung inflation in adult respiratory distress syndrome. Am J Respir Crit Care Med 149:8-13

18. Albert RK, Leasa D, Sanderson M, Robertson HT, Hlastala MP (1987) The prone position improves arterial oxygenation and reduces shunt in oleicacid-induced acute lung injury. Am Rev Respir Dis 135:628-633

19. Albert RK, Hubmayr RD (2000) The prone position eliminates compression of the lungs by the heart. Am J Respir Crit Care Med 161:1660-1665

20. Malbouisson LM, Busch CJ, Puybasset L, Lu Q, Cluzel P, Rouby JJ (2000) Role of the heart in the loss of aeration characterizing lower lobes in acute respiratory distress syndrome. CT Scan ARDS study group. Am J Respir Crit Care Med 161:2005-2012

21. Gattinoni L, Vagginelli F, Carlesso E, Taccone P, Conte V, Chiumello D, Valenza F, Caironi P, Pesenti A (2003) Decrease in $\mathrm{PaCO} 2$ with prone position is predictive of improved outcome in acute respiratory distress syndrome. Crit Care Med 31:2727-2733

22. Protti A, Chiumello D, Cressoni M, Carlesso E, Mietto C, Berto V, Lazzerin M, Quintel M, Gattinoni L (2009) Relationship between gas exchange response to prone position and lung recruitability during acute respiratory failure. Intensive Care Med 35:1011-1017

23. Guerin C, Beuret P, Constantin JM, Bellani G, Garcia-Olivares P, Roca O, Meertens JH, Maia PA, Becher T, Peterson J, Larsson A, Gurjar M, Hajjej Z, Kovari F, Assiri AH, Mainas E, Hasan MS, Morocho-Tutillo DR, Baboi L, Chretien JM, Francois G, Ayzac L, Chen L, Brochard L, Mercat A (2018) A prospective international observational prevalence study on prone positioning of ARDS patients: the APRONET (ARDS Prone Position Network) study. Intensive Care Med 44:22-37

24. Guérin C, Reignier J, Richard J-C, Beuret P, Gacouin A, Boulain T, Mercier E, Badet M, Mercat A, Baudin O, Clavel M, Chatellier D, Jaber S, Rosselli S, Mancebo J, Sirodot M, Hilbert G, Bengler C, Richecoeur J, Gainnier M, Bayle F, Bourdin G, Leray V, Girard R, Baboi L, Ayzac L (2013) Prone positioning in severe acute respiratory distress syndrome. N Engl I Med 368:2159-2168

25. Hering R, Wrigge H, Vorwerk R, Brensing KA, Schroder S, Zinserling J, Hoeft A, Spiegel TV, Putensen C (2001) The effects of prone positioning on intraabdominal pressure and cardiovascular and renal function in patients with acute lung injury. Anesth Analg 92:1226-1231

26. Bloomfield R, Noble DW (2014) Systematic review of prone positioning: study selection and analysis. Crit Care Med 42:e598-599

27. Chiumello D, Cressoni M, Racagni M, Landi L, Li Bassi G, Polli F, Carlesso E, Gattinoni L (2006) Effects of thoraco-pelvic supports during prone position in patients with acute lung injury/acute respiratory distress syndrome: a physiological study. Crit Care 10:R87

28. Jozwiak M, Teboul JL, Anguel N, Persichini R, Silva S, Chemla D, Richard C, Monnet X (2013) Beneficial hemodynamic effects of prone positioning in patients with acute respiratory distress syndrome. Am J Respir Crit Care Med 188:1428-1433

29. Vieillard-Baron A, Charron C, Caille V, Belliard G, Page B, Jardin F (2007) Prone positioning unloads the right ventricle in severe ARDS. Chest 132:1440-1446

30. Mekontso Dessap A, Boissier F, Charron C, Begot E, Repesse X, Legras A, Brun-Buisson C, Vignon P, Vieillard-Baron A (2016) Acute cor pulmonale during protective ventilation for acute respiratory distress syndrome: prevalence, predictors, and clinical impact. Intensive Care Med 42:862-870
31. Jardin F, Vieillard-Baron A (2007) Is there a safe plateau pressure in ARDS? The right heart only knows. Intensive Care Med 33:444-447

32. Rialp G, Betbese AJ, Perez-Marquez M, Mancebo J (2001) Short-term effects of inhaled nitric oxide and prone position in pulmonary and extrapulmonary acute respiratory distress syndrome. Am J Respir Crit Care Med 164:243-249

33. Cavalcanti AB, Suzumura EA, Laranjeira LN, Paisani DM, Damiani LP, Guimaraes HP, Romano ER, Regenga MM, Taniguchi LNT, Teixeira C, Pinheiro de Oliveira R, Machado FR, Diaz-Quijano FA, Filho MSA, Maia IS, Caser EB, Filho WO, Borges MC, Martins PA, Matsui M, Ospina-Tascon GA, Giancursi TS, Giraldo-Ramirez ND, Vieira SRR, Assef M, Hasan MS, Szczeklik W, Rios F, Amato MBP, Berwanger O, Ribeiro de Carvalho CR (2017) Effect of lung recruitment and titrated positive end-expiratory pressure (PEEP) vs low PEEP on mortality in patients with acute respiratory distress syndrome: a randomized clinical trial. JAMA 318:1335-1345

34. Albert RK, Keniston A, Baboi L, Ayzac L, Guérin C (2014) Prone positioninduced improvement in gas exchange does not predict improved survival in the acute respiratory distress syndrome. Am J Respi Crit Care Med 189:494-496

35. Broccard AF, Shapiro RS, Schmitz LL, Ravenscraft SA, Marini JJ (1997) Influence of prone position on the extent and distribution of lung injury in a high tidal volume oleic acid model of acute respiratory distress syndrome. Crit Care Med 25:16-27

36. Broccard A, Shapiro RS, Schmitz LL, Adams AB, Nahum A, Marini JJ (2000) Prone positioning attenuates and redistributes ventilator-induced lung injury in dogs. Crit Care Med 28:295-303

37. Albert RK (2020) Prone ventilation for mild or moderate acute respiratory distress syndrome. Ann Am Thorac Soc 17:24-29

38. Albert RK (1999) Prone position in ARDS: what do we know, and what do we need to know? Crit Care Med 27:2574-2575

39. Beitler JR, Shaefi S, Montesi SB, Devlin A, Loring SH, Talmor D, Malhotra A (2014) Prone positioning reduces mortality from acute respiratory distress syndrome in the low tidal volume era: a meta-analysis. Intensive Care Med 40:332-341

40. Cornejo RA, Diaz JC, Tobar EA, Bruhn AR, Ramos CA, Gonzalez RA, Repetto CA, Romero CM, Galvez LR, Llanos O, Arellano DH, Neira WR, Diaz GA, Zamorano AJ, Pereira GL (2013) Effects of prone positioning on lung protection in patients with acute respiratory distress syndrome. Am J Respir Crit Care Med 188:440-448

41. Beitler JR, Guerin C, Ayzac L, Mancebo J, Bates DM, Malhotra A, Talmor D (2015) PEEP titration during prone positioning for acute respiratory distress syndrome. Crit Care 19:436

42. Kumaresan A, Robert Gerber R, Mueller A, Loring SH, Talmor D (2018) Effects of prone positioning on transpulmonary pressures and endexpiratory volumes in patients without lung disease. Anesthesiology 128:1187-1192

43. Scholten EL, Beitler JR, Prisk GK, Malhotra A (2017) Treatment of ARDS with prone positioning. Chest 151:215-224

44. van Meenen DM, Roozeman JP, Neto AS, Pelosi P, de Abreu MG, Horn J, Cremer OL, Paulus F, Schultz MJ, Consortium M (2019) Associations between changes in oxygenation, dead space and driving pressure induced by the first prone position session and mortality in patients with acute respiratory distress syndrome. J Thorac Dis 11:5004-5013

45. Gattinoni L, Marini JJ, Pesenti A, Quintel M, Mancebo J, Brochard L (2016) The "baby lung" became an adult. Intensive Care Med 42:663-673

46. Schmidt M, Pham T, Arcadipane A, Agerstrand C, Ohshimo S, Pellegrino V, Vuylsteke A, Guervilly C, McGuinness S, Pierard S, Breeding J, Stewart C, Ching SSW, Camuso JM, Stephens RS, King B, Herr D, Schultz MJ, Neuville M, Zogheib E, Mira JP, Roze H, Pierrot M, Tobin A, Hodgson C, Chevret S, Brodie D, Combes A (2019) Mechanical ventilation management during extracorporeal membrane oxygenation for acute respiratory distress syndrome. An international multicenter prospective cohort. Am J Respir Crit Care Med 200:1002-1012

47. Robak O, Schellongowski P, Bojic A, Laczika K, Locker GJ, Staudinger T (2011) Short-term effects of combining upright and prone positions in patients with ARDS: a prospective randomized study. Crit Care 15:R230

48. Taccone P, Pesenti A, Latini R, Polli F, Vagginelli F, Mietto C, Caspani L, Raimondi F, Bordone G, lapichino G, Mancebo J, Guerin C, Ayzac L, Blanch L, Fumagalli R, Tognoni G, Gattinoni L (2009) Prone positioning in patients with moderate and severe acute respiratory distress syndrome: a randomized controlled trial. JAMA 302:1977-1984 
49. Michelet P, Roch A, Gainnier M, Sainty JM, Auffray JP, Papazian L (2005) Influence of support on intra-abdominal pressure, hepatic kinetics of indocyanine green and extravascular lung water during prone positioning in patients with ARDS: a randomized crossover study. Crit Care 9:R251-257

50. Guervilly C, Hraiech S, Gariboldi V, Xeridat F, Dizier S, Toesca R, Forel JM, Adda M, Grisoli D, Collart F, Roch A, Papazian L (2014) Prone positioning during veno-venous extracorporeal membrane oxygenation for severe acute respiratory distress syndrome in adults. Minerva Anestesiol 80:307-313

51. Kimmoun A, Guerci P, Bridey C, Ducrocq N, Vanhuyse F, Levy B (2013) Prone positioning use to hasten veno-venous ECMO weaning in ARDS. Intensive Care Med 39:1877-1879

52. Abroug F, Ouanes-Besbes L, Dachraoui F, Ouanes I, Brochard L (2011) An updated study-level meta-analysis of randomised controlled trials on proning in ARDS and acute lung injury. Crit Care 15:R6

53. McAuley DF, Giles S, Fichter H, Perkins GD, Gao F (2002) What is the optimal duration of ventilation in the prone position in acute lung injury and acute respiratory distress syndrome? Intensive Care Med 28:414-418

54. Haddam M, Zieleskiewicz L, Perbet S, Baldovini A, Guervilly C, Arbelot C, Noel A, Vigne C, Hammad E, Antonini F, Lehingue S, Peytel E, Lu Q, Bouhemad B, Golmard JL, Langeron O, Martin C, Muller L, Rouby JJ, Constantin JM, Papazian L, Leone M, Network CAEC, AzuRea Collaborative N (2016) Lung ultrasonography for assessment of oxygenation response to prone position ventilation in ARDS. Intensive Care Med 42:1546-1556

55. Papazian L, Paladini MH, Bregeon F, Thirion X, Durieux O, Gainnier M, Huiart L, Agostini S, Auffray JP (2002) Can the tomographic aspect characteristics of patients presenting with acute respiratory distress syndrome predict improvement in oxygenation-related response to the prone position? Anesthesiology 97:599-607

56. Constantin JM, Jabaudon M, Lefrant JY, Jaber S, Quenot JP, Langeron O, Ferrandiere M, Grelon F, Seguin P, Ichai C, Veber B, Souweine B, Uberti T, Lasocki S, Legay F, Leone M, Eisenmann N, Dahyot-Fizelier C, Dupont $\mathrm{H}_{\text {, }}$ Asehnoune K, Sossou A, Chanques G, Muller L, Bazin JE, Monsel A, Borao L, Garcier JM, Rouby JJ, Pereira B, Futier E, Network A (2019) Personalised mechanical ventilation tailored to lung morphology versus low positive end-expiratory pressure for patients with acute respiratory distress syndrome in France (the LIVE study): a multicentre, single-blind, randomised controlled trial. Lancet Respir Med 7:870-880

57. Grant GP, Szirth BC, Bennett HL, Huang SS, Thaker RS, Heary RF, Turbin RE (2010) Effects of prone and reverse trendelenburg positioning on ocular parameters. Anesthesiology 112:57-65

58. Munshi L, Del Sorbo L, Adhikari NKJ, Hodgson CL, Wunsch H, Meade MO, Uleryk E, Mancebo J, Pesenti A, Ranieri VM, Fan E (2017) Prone position for acute respiratory distress syndrome. A systematic review and metaanalysis. Ann Am Thorac Soc 14:S280-S288

59. Lucchini A, Bambi S, Mattiussi E, Elli S, Villa L, Bondi H, Rona R, Fumagalli $R$, Foti G (2020) Prone position in acute respiratory distress syndrome patients: a retrospective analysis of complications. Dimens Crit Care Nurs 39:39-46

60. Girard R, Baboi L, Ayzac L, Richard JC, Guerin C, Proseva trial g (2014) The impact of patient positioning on pressure ulcers in patients with severe ARDS: results from a multicentre randomised controlled trial on prone positioning. Intensive Care Med 40:397-403

61. Guerin C, Badet M, Rosselli S, Heyer L, Sab JM, Langevin B, Philit F, Fournier G, Robert D (1999) Effects of prone position on alveolar recruitment and oxygenation in acute lung injury. Intensive Care Med 25:1222-1230

62. Gattinoni L, Tognoni G, Pesenti A, Taccone P, Mascheroni D, Labarta V Malacrida R, Di Giulio P, Fumagalli R, Pelosi P, Brazzi L, Latini R (2001) Effect of prone positioning on the survival of patients with acute respiratory failure. N Engl J Med 345:568-573

63. Guerin C, Gaillard S, Lemasson S, Ayzac L, Girard R, Beuret P, Palmier B, Le QV, Sirodot M, Rosselli S, Cadiergue V, Sainty J-M, Barbe P, Combourieu E, Debatty D, Rouffineau J, Ezingeard E, Millet O, Guelon D, Rodriguez L, Martin O, Renault A, Sibille J-P, Kaidomar M (2004) Effects of systematic prone positioning in hypoxemic acute respiratory failure: a randomized controlled trial. JAMA 292:2379-2387
64. Mancebo J, Fernandez R, Blanch L, Rialp G, Gordo F, Ferrer M, Rodriguez F, Garro P, Ricart P, Vallverdu I, Gich I, Castano J, Saura P, Dominguez G, Bonet A, Albert RK (2006) A multicenter trial of prolonged prone ventilation in severe acute respiratory distress syndrome. Am J Respir Crit Care Med 173:1233-1239

65. Adhikari NK, Dellinger RP, Lundin S, Payen D, Vallet B, Gerlach H, Park KJ, Mehta S, Slutsky AS, Friedrich JO (2014) Inhaled nitric oxide does not reduce mortality in patients with acute respiratory distress syndrome regardless of severity: systematic review and meta-analysis. Crit Care Med 42:404-412

66. Gattinoni L, Carlesso E, Taccone P, Polli F, Guerin C, Mancebo J (2010) Prone positioning improves survival in severe ARDS: a pathophysiologic review and individual patient meta-analysis. Minerva Anestesiol 76:448-454

67. Fan E, Del Sorbo L, Goligher EC, Hodgson CL, Munshi L, Walkey AJ, Adhikari NKJ, Amato MBP, Branson R, Brower RG, Ferguson ND, Gajic O, Gattinoni L, Hess D, Mancebo J, Meade MO, McAuley DF, Pesenti A, Ranieri VM, Rubenfeld GD, Rubin E, Seckel M, Slutsky AS, Talmor D, Thompson BT, Wunsch H, Uleryk E, Brozek J, Brochard L (2017) An Official American Thoracic Society/European Society of Intensive Care Medicine/Society of Critical Care Medicine Clinical Practice Guideline: mechanical ventilation in adult patients with acute respiratory distress syndrome. Am J Respir Crit Care Med 195:1253-1263

68. Papazian L, Aubron C, Brochard L, Chiche JD, Combes A, Dreyfuss D, Forel JM, Guerin C, Jaber S, Mekontso-Dessap A, Mercat A, Richard JC, Roux D, Vieillard-Baron A, Faure H (2019) Formal guidelines: management of acute respiratory distress syndrome. Ann Intensive Care 9:69

69. Ferrando C, Suarez-Sipmann F, Mellado-Artigas R, Hernandez M, Gea A, Arruti E, Aldecoa C, Martinez-Palli G, Martinez-Gonzalez MA, Slutsky AS, Villar J, Network C-SI (2020) Clinical features, ventilatory management, and outcome of ARDS caused by COVID-19 are similar to other causes of ARDS. Intensive Care Med. https://doi.org/10.1007/s00134-020-06192-2

70. Zarantonello F, Andreatta G, Sella N, Navalesi P (2020) Prone position and lung ventilation and perfusion matching in acute respiratory failure due to COVID-19. Am J Respir Crit Care Med 202:278-279

71. Gattinoni L, Chiumello D, Caironi P, Busana M, Romitti F, Brazzi L, Camporota $L$ (2020) COVID-19 pneumonia: different respiratory treatments for different phenotypes? Intensive Care Med 46:1099-1102

72. Jochmans S, Mazerand S, Chelly J, Pourcine F, Sy O, Thieulot-Rolin N, Ellrodt O, Mercier Des Rochettes E, Michaud G, Serbource-Goguel J, Vinsonneau C, Vong LVP, Monchi M (2020) Duration of prone position sessions: a prospective cohort study. Ann Intensive Care 10:66

73. Dalla Corte F, Mauri T, Spinelli E, Lazzeri M, Turrini C, Albanese M, Abbruzzese C, Lissoni A, Galazzi A, Eronia N, Bronco A, Maffezzini E, Pesenti A, Foti G, Bellani G, Grasselli G (2020) Dynamic bedside assessment of the physiologic effects of prone position in acute respiratory distress syndrome patients by electrical impedance tomography. Minerva Anestesiol 86:1057-1064

74. Mezidi M, Parrilla FJ, Yonis H, Riad Z, Bohm SH, Waldmann AD, Richard JC, Lissonde F, Tapponnier R, Baboi L, Mancebo J, Guerin C (2018) Effects of positive end-expiratory pressure strategy in supine and prone position on lung and chest wall mechanics in acute respiratory distress syndrome. Ann Intensive Care 8:86

75. Scaramuzzo G, Ball L, Pino F, Ricci L, Larsson A, Guérin C, Pelosi P, Perchiazzi $G$ (2020) Influence of PEEP titration on the effects of pronation in ARDS: a comprehensive experimental study. Front Physiol 11:1-10

76. Coppo A, Bellani G, Winterton D, Di Pierro M, Soria A, Faverio P, Cairo M, Mori S, Messinesi G, Contro E, Bonfanti P, Benini A, Valsecchi MG, Antolini L, Foti G (2020) Feasibility and physiological effects of prone positioning in non-intubated patients with acute respiratory failure due to COVID-19 (PRON-COVID): a prospective cohort study. Lancet Respir Med 8:765-774

77. Ferrando C, Mellado-Artigas R, Gea A, Arruti E, Aldecoa C, Adalia R, Ramasco F, Monedero P, Maseda E, Tamayo G, Hernandez-Sanz ML, Mercadal J, Martin-Grande A, Kacmarek RM, Villar J, Suarez-Sipmann F, Network C-SI (2020) Awake prone positioning does not reduce the risk of intubation in COVID-19 treated with high-flow nasal oxygen therapy: a multicenter, adjusted cohort study. Crit Care 24:597 